\title{
About the research in indigenous populations
}

Renato Antunes Dos Santos, MD, PhD; Eduardo Chachamovich, MD, PhD.

McGill University, Department of Psychiatry, Montréal, Canada

Douglas Mental Health University Institute

Contact: renato.antunes@mail.mcgill.ca

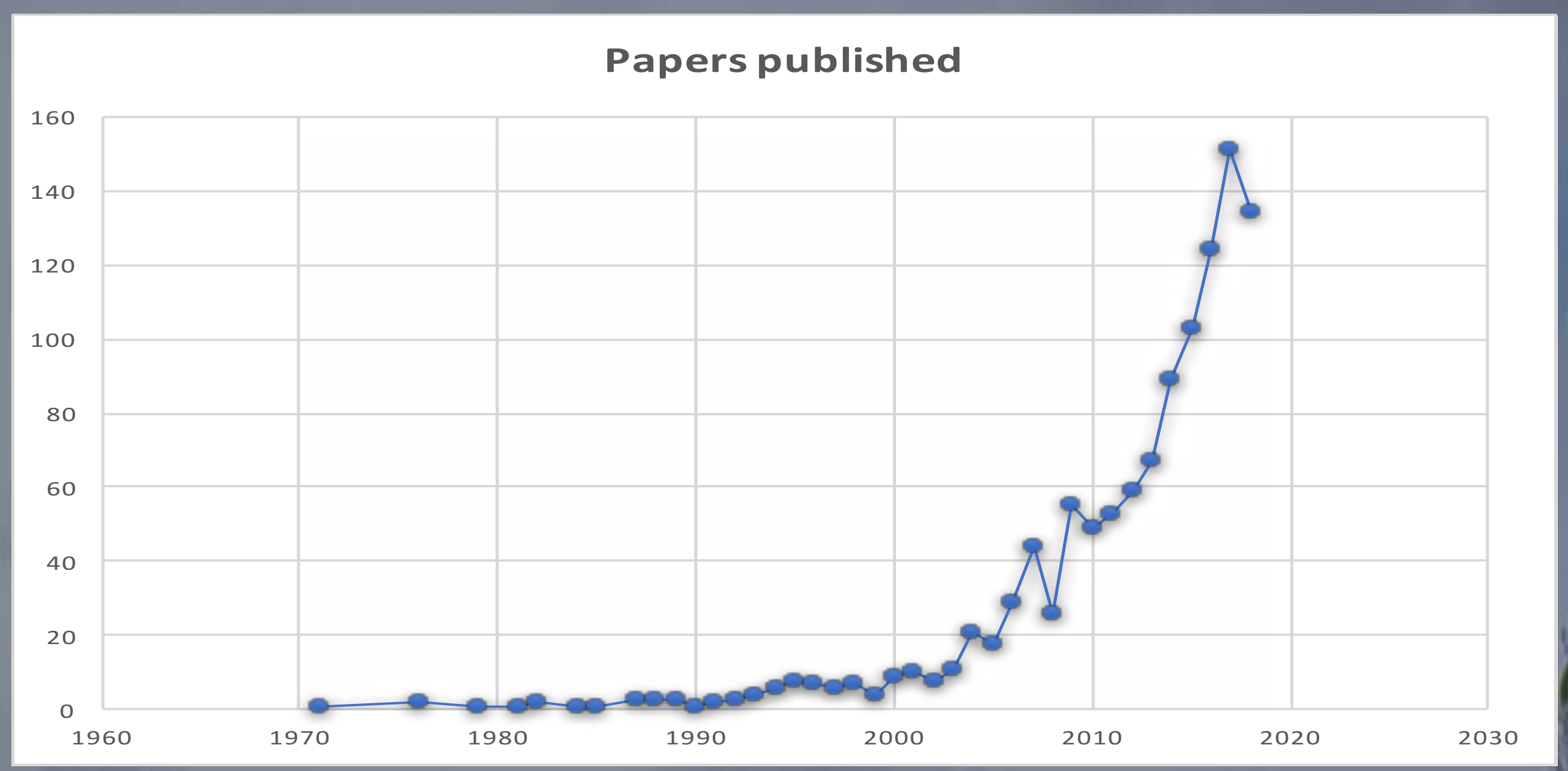

Figure 1: Health-related Indigenous Quality of Life and Wellbeing.

Objectives: This study discusses the potential impact of the academic massive production on Indigenous Mental Health.

Background: The world has been facing increasing suicide rates ${ }^{1}$. Considering the indigenous populations, rates can achieve 30 times the average for young men of the same

country ${ }^{2}$. Beyond the typical suicide' risk factors, aspects such as the intergenerational trauma, colonization, rapid social and cultural changes, and substance abuse play a major role in the rates of suicide among Indigenous populations ${ }^{3}$. In order to improve indigenous quality of life and prevent suicides, researchers have been engaging several studies in this field. In the last years, the amount of studies concerning mental health (e.g. suicide and quality of life) among indigenous have been calling attention. The number of publications is compatible with the massive production of research papers imposed by an academic life (figure 1) however, there are critics about the risks of 'overstudying' such small populations. There is an unanswered question about the safe levels to a person become subject of research.

Materials and Methods:

Literature review and critical analyses.

Results, Discussion and Conclusions:

There have been many critics of the massive academic production leading to

poor or none impact on society. The indigenous people are not an exception of a population sometimes 'overstudied' resulting in none, or even negative, impact ${ }^{4}$. Often living in health disadvantage, a vulnerable population might internalize the constant 'deficit' assessments' as messages reducing expectations and aspirations ${ }^{5}$. When a

small population is so massively researched, especially focusing on their impairments, the research per se might have a potentially, negative impact on mental health. This risk is hard to be evaluated, but cannot be unvalued. By guaranteeing the maintenance of the heritage, longterm' impact, knowledge transference, and indigenous participation in all phases of the research might put the balance back to the positive side of the research interventions. 